\title{
XRCC5 VNTR, XRCC6 -61C >G, and XRCC7 6721G>T Gene Polymorphisms Associated with Male Infertility Risk: Evidences from Case-Control and In Silico Studies
}

\author{
Danial Jahantigh and Abasalt Hosseinzadeh Colagar \\ Department of Molecular and Cell Biology, Faculty of Basic Sciences, University of Mazandaran, Babolsar, Iran \\ Correspondence should be addressed to Abasalt Hosseinzadeh Colagar; colagar@yahoo.com
}

Received 16 October 2016; Revised 26 December 2016; Accepted 4 January 2017; Published 21 March 2017

Academic Editor: Małgorzata Kotula-Balak

Copyright ( 2017 Danial Jahantigh and Abasalt Hosseinzadeh Colagar. This is an open access article distributed under the Creative Commons Attribution License, which permits unrestricted use, distribution, and reproduction in any medium, provided the original work is properly cited.

\begin{abstract}
We evaluate the association between genetic polymorphisms of XRCC5 VNTR, XRCC6 -61C>G, and XRCC7 6721G>T with male infertility susceptibility. A total of 392 men including 178 infertile males (102 idiopathic azoospermia and 76 severe oligozoospermia) and 214 healthy controls were recruited. XRCC6 $-61 \mathrm{C}>\mathrm{G}$ and XRCC7 $6721 \mathrm{G}>\mathrm{T}$ genotyping was performed by PCR-RFLP whereas XRCC5 VNTR was performed by PCR. The 2R allele and 2R allele carriers of XRCC5 VNTR polymorphism significantly decreased risk of male infertility. The mutant GG genotypes and carriers of the CG and GG genotypes of XRCC6 $-61 \mathrm{C}>\mathrm{G}$ showed increased risk for the male infertility. Furthermore, the $\mathrm{G}$ allele of the XRCC6 -61C>G was correlated with increased susceptibility to male infertility. Likewise, the $\mathrm{T}$ allele of the XRCC7 $6721 \mathrm{G}>\mathrm{T}$ polymorphism was associated with increased susceptibility to male infertility in azoospermia. In silico analysis predicted that the presence of tandem repeats in XRCC5 gene prompter can be sequence to bind to more nuclear factors. Also, rs2267437 (C>G) variant was located in a well-conserved region in XRCC6 promoter and this variation might lead to differential allelic expression. The XRCC7 6721G>T gene polymorphism occurred in an acceptor-splicing site, but this polymorphism has no severe modification on XRCC7 mRNA splicing. Our results indicate the association of XRCC5 VNTR, XRCC6 -61C>G, and XRCC7 $6721 \mathrm{G}>\mathrm{T}$ gene polymorphisms with male infertility in Iranian men.
\end{abstract}

\section{Introduction}

Male infertility is responsible for $40-50 \%$ infertility problems which affects up to one in six couples worldwide [1]. However, the exact etiology and pathogenesis of approximately half of the male infertility cases remains unknown yet, and it is well known as idiopathic infertility. Some evidences declared that DNA damage in human spermatozoa is associated with poor semen quality and low fertilization rates for both in vitro and in vivo fertility, suggesting that sperm DNA damage could be used as a potential predictor of fertility $[2,3]$.

Defects in DNA repair pathways during spermatogenesis have negative effects on the integrity of sperm DNA; could decrease quality and quantity of sperm including morphology, movement, and number; and cause infertility [4-6].
DNA damages, single strand breaks (SSBs), and double strand breaks (DSBs) are induced by exogenous and endogenous agents such as ionizing radiation (IR), oxidative and replication stress, and naturally programmed processes including meiotic and V(D)J recombination ([7-10]; Zha et al. 2007). The DSB is the most harmful form which should be repaired with homologuos recombination (HR) or predominantly nonhomologous end joining (NHEJ) $[9,10]$. NHEJ involves binding of the $\mathrm{Ku}$ protein, Ku70 (XRCC6)/80 (XRCC5) heterodimer, to broken DNA ends, which induces inward translocation of $\mathrm{Ku}$ and recruits the DNA-PK catalytic subunit (DNA-PKcs) (XRCC7), to the ends of the DSB to form DNA-dependent protein kinase (DNA-PK) [10]. All components of the DNA-PK, including Ku70, Ku80, and DNAPKcs, were found in the radiosensitive spermatogonia, so that the Ku70 and/or Ku80-deficient testis displays 
TABLE 1: Demographic and clinical characteristics of participants.

\begin{tabular}{|c|c|c|c|c|c|c|c|}
\hline Variable & $\begin{array}{l}\text { Control } \\
(n=214)\end{array}$ & $\begin{array}{c}\text { Total } \\
(n=178)\end{array}$ & $\begin{array}{c}\text { Patients } \\
\text { AS } \\
(n=102)\end{array}$ & $\begin{array}{c}\text { Severe OS } \\
(n=76)\end{array}$ & $\begin{array}{c}\text { Control versus } \\
\text { total }\end{array}$ & $\begin{array}{c}p \text { value } \\
\text { Control versus } \\
\text { AS }\end{array}$ & $\begin{array}{c}\text { Control versus } \\
\text { severe OS }\end{array}$ \\
\hline Age (years: mean $\pm S D)$ & $31.6 \pm 4.4$ & $32.3 \pm 2.7$ & $32.05 \pm 4.1$ & $31.8 \pm 3.6$ & 0.191 & 0.540 & 0.582 \\
\hline \multicolumn{8}{|l|}{ Body mass index $\left(\mathrm{kg} / \mathrm{m}^{2}\right)(\%)$} \\
\hline$\leq 24.9$ & 27.1 & 25.8 & 23.5 & 28.9 & & & \\
\hline $25-34.9$ & 66.3 & 64.04 & 64.7 & 63.1 & & & \\
\hline$\geq 35$ & 6.5 & 10.1 & 11.7 & 7.8 & 0.201 & 0.119 & 0.689 \\
\hline \multicolumn{8}{|l|}{ Smoking (\%) } \\
\hline Yes & 30.8 & 34.8 & 37.2 & 31.5 & & & \\
\hline No & 69.1 & 65.1 & 62.7 & 68.4 & 0.401 & 0.257 & 0.904 \\
\hline \multicolumn{8}{|l|}{ Semen analysis (\%) } \\
\hline (1) Sperm count $\leq 20($ million $/ m L)$ & 0 & 100 & 100 & 100 & $<0.001$ & $<0.001$ & $<0.001$ \\
\hline \multicolumn{8}{|l|}{ (2) Motility (grade $a+b$ ) } \\
\hline$\geq 50$ & 68.2 & 10.1 & 9.8 & 10.5 & & & \\
\hline$<50$ & 31.7 & 89.8 & 90.1 & 89.4 & $<0.001$ & $<0.001$ & $<0.001$ \\
\hline \multicolumn{8}{|l|}{ (3) Viscosity } \\
\hline$\leq 30 \mathrm{~min}$ & 57.9 & 73.03 & 72.5 & 73.6 & & & \\
\hline$>30 \mathrm{~min}$ & 42.05 & 26.9 & 27.4 & 26.3 & 0.316 & 0.251 & 0.694 \\
\hline \multicolumn{8}{|l|}{ (4) Normal morphology } \\
\hline$\geq 30 \%$ & 34.5 & 13.4 & 11.7 & 15.78 & & & \\
\hline$<30 \%$ & 65.4 & 86.5 & 88.2 & 84.2 & 0.001 & 0.004 & 0.004 \\
\hline
\end{tabular}

AS: azoospermia, OS: oligozoospermia.

elevated levels of DSBs as well as enhanced apoptosis and reduced sperm production [11-15]. It is reported that $\mathrm{Ku}$ proteins are downregulated in early meiotic cells, but are again expressed in late pachytene and diplotene spermatocytes, and they mediate repair proficiency in somatic cells of the testis, thereby assuring the fidelity of spermatogenesis [11-13].

Strong evidences support the relationship between genetic polymorphism of genes involved in DNA repair pathways with extra sperm DNA damage and male infertility risk [16-21]. Among several genetic variants of the XRCC5, XRCC6, and XRCC7, a novel variable number of tandem repeats (VNTR) in the promoter region of $X R C C 5$ and two single nucleotide polymorphisms (SNPs) XRCC6 -61C>G and XRCC7 6721G $>$ T located in the promoter region of XRCC6 and intron 8 of XRCC7 genes, respectively, have been extensively studied in various disorders such as cancer [22-29] and autoimmune diseases $[30,31]$, but whether genetic variants in these repair pathway genes affect susceptibility to male infertility remains unknown.

Since the Ku protein, Ku70 (XRCC6)/80 (XRCC5), and DNA-PKcs (XRCC7) as critical components of NHEJ play important role in DNA integrity of spermatogenesis and can affect the offspring, we hypothesize that genetic variation of these genes may contribute to male infertility risk. Therefore, in current study, we evaluated possible relation between these common and functional polymorphisms with male infertility risk in a case-control study, and also, in silico analysis was carried out to investigate the effects of these
SNPs on the interaction of several factors and motifs, involved in transcription and mRNA splicing.

\section{Material and Methods}

2.1. Patients and Control Samples. A total of 178 infertile patients, including 102 men with idiopathic nonobstructive azoospermia and 76 men with severe oligozoospermia (semen count less than $5 \times 10^{6} / \mathrm{mL}$ ), aged $24-39$ years, and mean $31.6 \pm 4.4$ years, were recruited from the Fatemeh Zahra In Vitro Fertilization (IVF) Center in Babol, Iran, between 2013 and 2015 (Table 1). Semen samples were obtained by masturbation into sterile tubes after sexual abstinence for 2 to 3 days. Before semen analysis, a questionnaire was distributed to obtain information on smoking habits, alcohol use, use or abuse of other substances and drugs, and a history of reproductive system diseases. The samples with known causes of infertility were excluded; therefore, the patients with history of cryptorchidism, orchitis, obstruction of the vas deferens, varicocele, infectious diseases, drug abuse, diabetes mellitus, abnormal hormone profile ( $\mathrm{LH}$, FSH, and testosterone), Y-chromosome microdeletion, and abnormal karyotype were excluded from the study. So, only men with idiopathic infertility were included in the study. All patients underwent at least two semen analyses according to World Health Organization (WHO) guidelines after 3-5 days of sexual abstinence. The control group consisted of 214 men who were proven fertile with normozoospermia aged from 23 to 48 years. These studies were approved by the Ethics Committees of University of Mazandaran 
and informed consent was obtained from each subject before participation.

2.2. DNA Extraction, PCR, and RFLP. Genomic DNA was extracted from blood samples, which were collected in $2 \mathrm{ml}$ $\mathrm{EDTA}_{\mathrm{Na} 2}$ tubes from patients and healthy controls, by using the commercial available kit (Roche, Germany). Extracted DNA was stored at $-20^{\circ} \mathrm{C}$. Fragments of the XRCC $3 \mathrm{R} / 2 \mathrm{R} /$ $1 \mathrm{R} / 0 \mathrm{R}-\mathrm{VNTR}, \mathrm{XRCC6}-61 \mathrm{C}>\mathrm{G}$ promoter, and XRCC7 $6721 \mathrm{G}>\mathrm{T}$ amplified by polymerase chain reaction (PCR) using XRCC5-f/-r, XRCC6-f/-r, and XRCC7-f/-r primers, which were designed by [26], and PCR conditions, were described by [30].

DNA fragments of the XRCC6 $-61 \mathrm{C}>\mathrm{G}$ and XRCC7 $6721 \mathrm{G}>\mathrm{T}$ were used in PCR-restriction fragment length polymorphism (PCR-RFLP) technique. Approximately $5 \mu \mathrm{l}$ $(\sim 0.1 \mu \mathrm{g})$ of the XRCC6 -61C $>\mathrm{G}$ and XRCC7 6721G $>\mathrm{T}$ amplified products were digested with 5 units of the BanI (with cut site: $5^{\prime}$-GGCGCC) and $P v u$ II (with cut site: $5^{\prime}$-CAGCTG), respectively. Digestion reactions were performed at the total volume $10 \mu \mathrm{l}$ with incubation at $37^{\circ} \mathrm{C}$ for $16 \mathrm{~h}$. PCR and/or digestion products were electrophoresed on a $3 \%$ agarose gel and visualized by ethidium bromide staining. All of the PCR and restriction reactants were purchased from CinnaGen Co, Iran. All of the electrophoresis materials were prepared from Merck Co, Germany.

2.3. In Silico Analysis. In silico analysis was performed to evaluate potential biological functions of two promoteric SNPs, rs6147172 and rs2267437, which are located in promoter region of XRCC5 and XRCC6 genes, respectively. Also, an intronic SNP, rs7003908, which is located in the intron 8 of XRCC7 gene, was subject of in silico analysis.

For detection of core promoter motifs, the DNA sequences that contain promoteric SNPs were screened by the prediction tools, EPD [32] and ElemeNT [33]. Also, SNPnexus [34] and PROMO [35] were used to find potential transcription factor binding sites in SNPs containing promoter sequences. The intronic sequence of XRCC7 gene that contains $6721 \mathrm{G}>\mathrm{T}$ mutation was analyzed by Human Splicing Finder version 3, HSF3 [36], SpliceAid 2 [37], and SplicePort [38] to predict the effects of this variation on XRCC7 mRNA splicing. Moreover, the conservation of the DNA sequences containing XRCC6 $-61 \mathrm{C}>\mathrm{G}$ and XRCC7 6721G>T sites were also evaluated by Golden Path [39] and further illustrated by WebLogo [40].

2.4. Statistical Analysis. Hardy-Weinberg equilibrium (HWE) was calculated for both the infertile and control groups (http://www.oege.org/software/Hardy-Weinberg.html). All data were analyzed using SPSS software version 18. Differences in frequency of alleles and genotypes were analyzed using the chi-square test or Fisher's exact test. The odds ratio (OR) and 95\% confidence intervals (CIs) were estimated. Two-tailed $p<0.05$ was considered statistically significant. According to our results, sample power was computed using STATA 10 software.

\section{Results}

3.1. Demographic Analysis. Demographic and clinical characteristics of infertile patients and controls have been mentioned in Table 1. The infertile men were different from fertile men in sperm count, sperm motility, and sperm morphology. However, no differences were found between the two groups in terms of semen viscosity, smoking habit, and body mass index. About $57.3 \%$ of the infertile men were azoospermic and $42.6 \%$ were severe oligospermic.

3.2. VNTR Analysis. The XRCC5 VNTR polymorphism analysis was performed for XRCC5 promoter, which contains four different alleles with three $21 \mathrm{bp}$ repeats (3R), two $21 \mathrm{bp}$ repeats $(2 R)$, one 21 bp repeat $(1 R)$, and zero repeat $(0 R)$. Results of the PCR products by XRCC5-f/XRCC5-r primers in the agarose gel electrophoresis showed that size of fragments is $287 \mathrm{bp}, 266 \mathrm{bp}, 245 \mathrm{bp}$, and $224 \mathrm{bp}$ for $3 \mathrm{R}, 2 \mathrm{R}$, $1 \mathrm{R}$, and $0 \mathrm{R}$ alleles, respectively (Figure 1 ).

The distributions of allelic and genotypic frequencies for $X R C C 5$ VNTR polymorphism have been summarized in Table 2. In VNTR polymorphism of XRCC5 (rs6147172), among 10 probable genotypes, we observed 8 and 7 of them in control and male infertile groups, respectively. As it has been shown in Table 2, significant differences were observed between total infertile, azoospermic, severe oligozoospermic, and control groups in XRCC5 VNTR genotypes and allele frequencies.

The $2 R / 2 R$ genotype has the highest frequency in total infertile, azoospermic, severe oligozoospermic, and control groups $(38.78,28.65$, and 26.45 versus 31.57 percent, resp.), in which differences between total and azoospermia patients compared to controls were statistically significant $(p=0.014, p=0.011$, resp.). Significant association between genotypic frequencies of $0 \mathrm{R} / 2 \mathrm{R}$ and $1 \mathrm{R} / 2 \mathrm{R}$ in total patients $(p=0.039, p=0.014$, resp.) and also azoospermia patients ( $p=0.014, p=0.015$, resp.) with controls were observed. The frequency of individuals with $0 \mathrm{R}$ allele $(0 \mathrm{R} / 0 \mathrm{R}, 0 \mathrm{R} / 1 \mathrm{R}$, and $0 \mathrm{R} / 2 \mathrm{R}$ genotypes) showed 1.6-fold increased risk of total infertility and was statistically different $(p=0.039)$. Moreover, high significant differences in frequencies of the $2 R$ allele carriers $(0 R / 2 R+1 R / 2 R+2 R / 2 R+2 R / 3 R)$, between total infertile and azoospermia, together with a slight association with severe oligozoospermia compared controls were found ( $p<0.0001, p<0.0001$, and $p=0.013$, resp.). The frequency of $2 \mathrm{R}$ allele of XRCC5 VNTR polymorphism was found significantly higher than $0 \mathrm{R}$ allele in total, azoospermic, and severe oligospermic patients compared to control group ( $p=0.0005, p=0.001$, and $p=0.01$, resp.).

3.3. PCR-RFLP Analysis. The $320 \mathrm{bp}$ PCR product contains XRCC6 $-61 \mathrm{C}>\mathrm{G}$ polymorphism digested by BanI (Fermentas Co., Lithuania) to 240 and $80 \mathrm{bp}$ fragments for $\mathrm{G}$ allele and a single $320 \mathrm{bp}$, no Ban I cleavage site, for $\mathrm{C}$ allele (Figures 2(a) and $\left.2\left(a^{\prime}\right)\right)$. The wild-type $\mathrm{G}$ allele of XRCC7 $6721 \mathrm{G}>\mathrm{T}$ polymorphism was $368 \mathrm{bp}$ size and had no $P v u$ II cleavage site, whereas mutant allele, $\mathrm{T}$ allele, was digested to 274 and $94 \mathrm{bp}$ fragments (Figures $2(\mathrm{~b})$ and $2\left(\mathrm{~b}^{\prime}\right)$ ). 


\section{IIIIIIIIIIIIIIIIII \\ NC_000002.12}

(216107658..216206293)

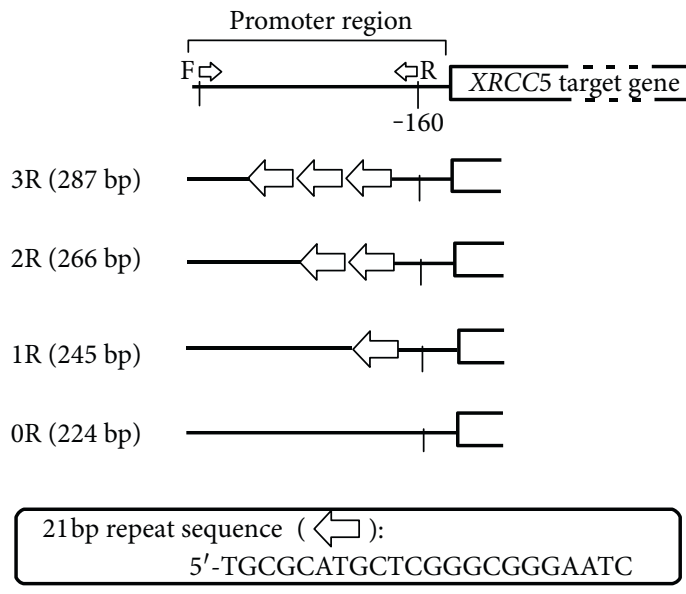

(a)

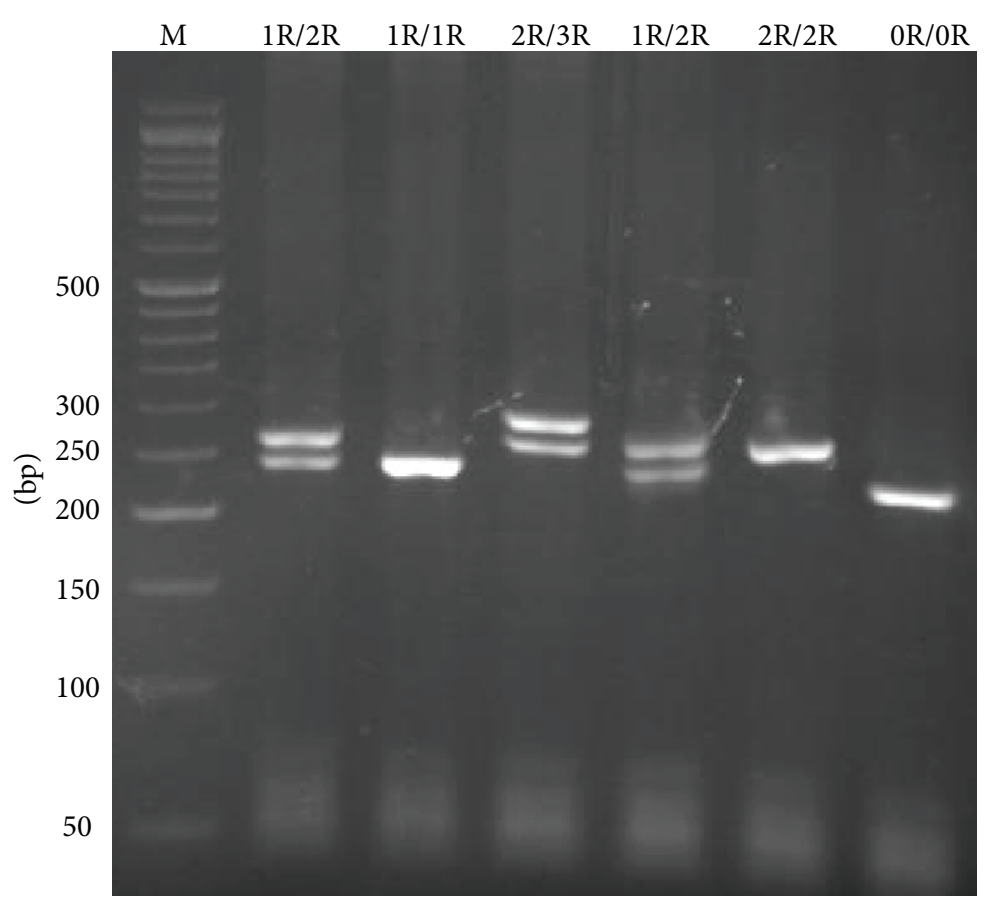

(b)

FIGURE 1: Schematic and PCR products of the XRCC5 VNTR: (a) schematic diagram of the XRCC5 gene showing the position of the VNTR polymorphism along with various alleles; (b) PCR products containing XRCC5 VNTR with various genotypes.

The allele and genotype frequencies of XRCC6 and $X R C C 7$ SNPs in male infertile patients and controls are summarized in Table 3. With regard to XRCC6 $-61 C>G$, the CG genotype in azoospermia was approximately 2 -fold higher than controls, which was significantly different $(p=0.003)$. The frequencies of the GG genotypes showed approximately 2.6, 3, and 2-fold increased risk of male infertility in total infertile, azoospermic, and severe oligospermic patients compared to control group, respectively, whose differences were statistically significant $(p=0.001, p=0.001$, and $p=0.043$, resp.). Furthermore, the $\mathrm{G}$ allele frequencies in total infertile and azoospermia were approximately 1.5and 2-fold higher than controls, and their differences were significant as well ( $p=0.001$ and $p=0.0002$, resp.).

Finally, XRCC7 -6721G $>$ T was evaluated in this study. Although mutant homozygotes and the $\mathrm{T}$ allele carriers $(\mathrm{GT}+\mathrm{TT})$ in azoospermic patients were 2.1 and 1.7-fold higher than control group, no significant differences were found ( $p=0.118$ and $p=0.247$, resp.) (Table 2). Likewise, the frequency of allele $\mathrm{T}$ in azoospermia was significantly higher than controls, which was statistically different $(p=030)$.

\subsection{Potential Biological Functions of XRCC5 VNTR, XRCC6} $-61 C>G$, and $X R C C 76721 G>T$. Since the genetic variants in promoter region can affect gene transcription activity via altering the DNA-binding ability of transcription factors, we consequently evaluated the potential biological functions of XRCC5 VNTR (rs6147172) and XRCC6 -61C>G (rs2267437) using bioinformatics analysis.

The XRCC5 VNTR was scanned for transcriptional start site (TSS) and core promoter elements by EPD and
ElemeNT. As shown in Figure 3(a), the VNTR of XRCC5 was located in downstream of the first TATA-box, -422 to -455 , in the promoter region and TSS. The various tandem repeats of XRCC5 have not shown any change in number of core promoter elements, such as TATA-box, Inr, DPE, $\mathrm{BRE}$, and DCE, but insertion of these tandem repeats moved these elements to upstream or downstream. The in vitro analysis demonstrated that four different alleles of XRCC5 VNTR $0 R, 1 R, 2 R$, and $3 R$ contain variable numbers of nuclear transcription factor Sp1 (Figure 3(b)) [27].

Additional in silico analysis of these polymorphic tandem repeat elements revealed several potential binding sites for transcription factors such as TFII-I, E2F-1, STAT4, and NF-kappa B (Figure 4). Furthermore, the allele with more tandem repeats, $2 \mathrm{R}$ and $3 \mathrm{R}$ alleles, includes more binding site elements than the one-repeat allele, suggesting that the presence of more tandem repeats could increase the affinity of transcription factors to the region of the XRCC5 promoter (Figure 4). The prediction of core promoter elements via ElemeNT tool showed that rs2267437 (C>G) causes deletion of a BRE upstream element in the XRCC6 promoter, and also, this mutation increased the score of near BRE upstream (Figure 5(a)). The XRCC6 -61C>G variant was predicted by SNPnexus and PROMO tools to be located in the core recognition site of transcription factor E2F1 in XRCC6 gene promoter, and the transversion of allele $\mathrm{C}$ to allele $\mathrm{G}$ would lead to the loss of E2F1 binding site (Figure 5(b)). The rs189037 (C>G) was demonstrated by Golden Path tool to be located in a well-conserved region across multiple mammalian species and such conservation was further illustrated in WebLogo (Figure 5(c)). 


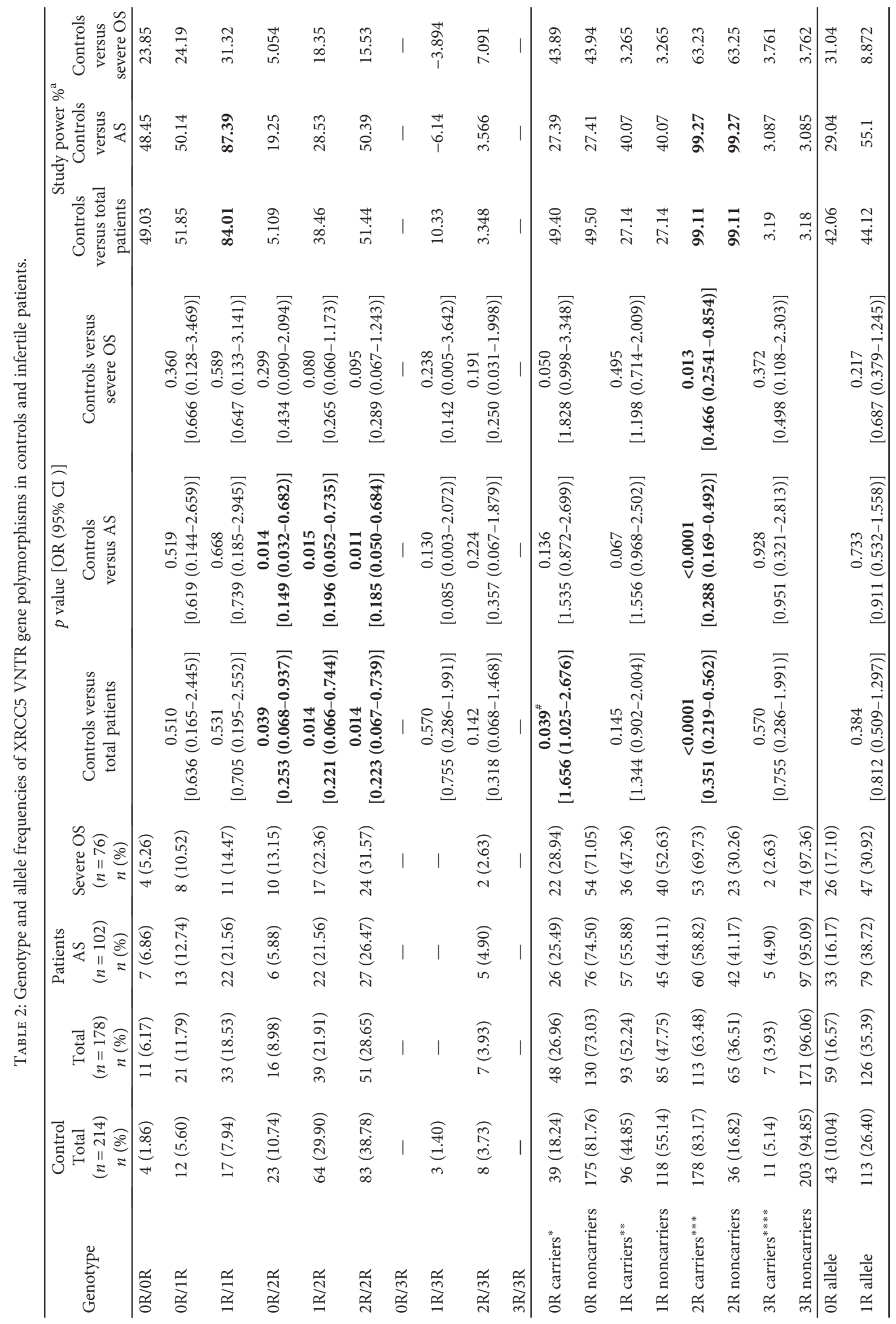




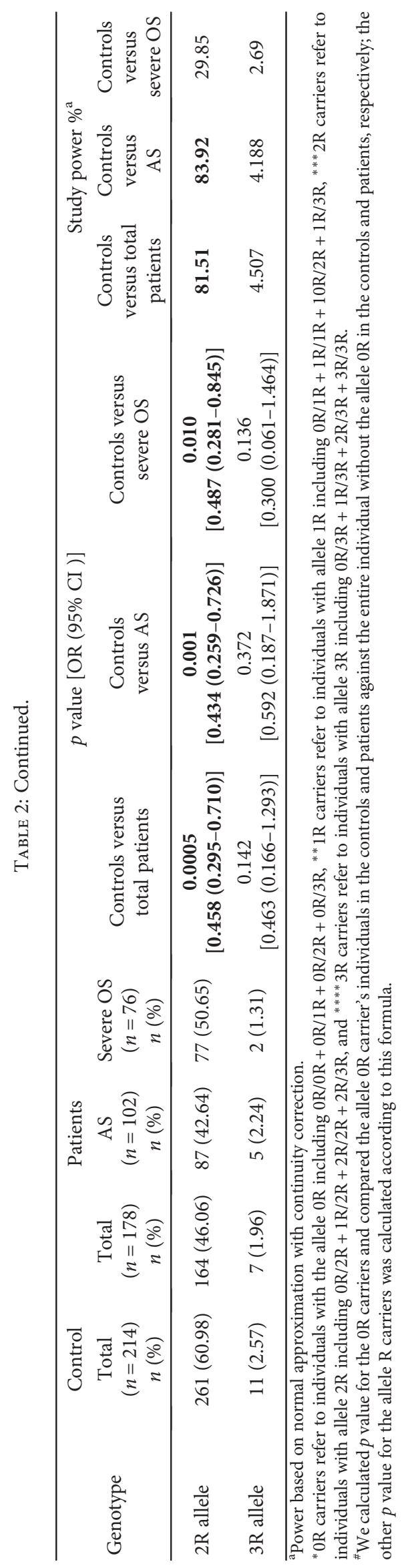




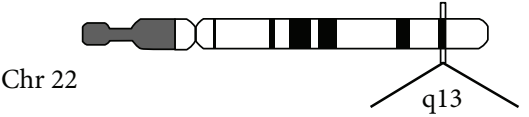

NC_000022.11

$(41621163 . .41664048)$

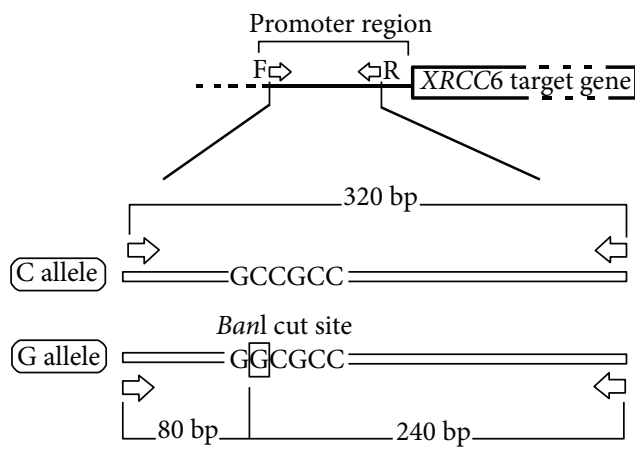

(a)

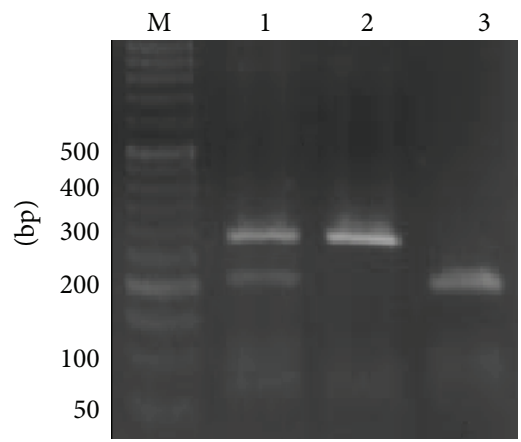

$\left(a^{\prime}\right)$
CIIIIIIIIIIIII

Chr 8

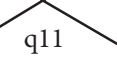

NC_000008.11

(47773108..47960183)

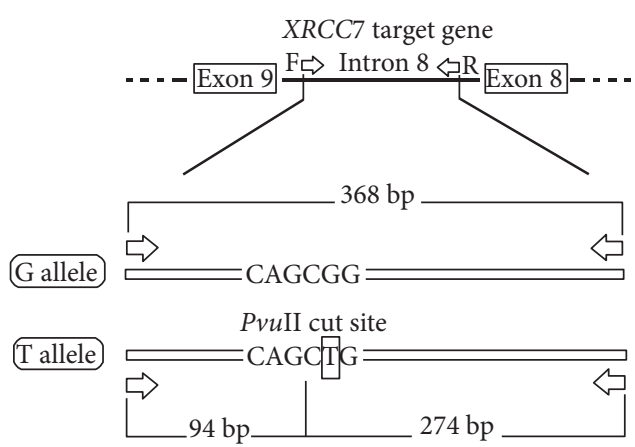

(b)

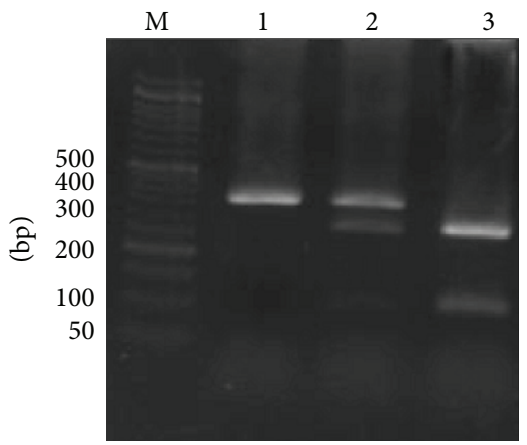

$\left(b^{\prime}\right)$

FIGURE 2: Schematic diagram and results of the PCR-RFLP products of XRCC6 and XRCC7: (a) schematic diagram of XRCC6 -61C>G, which showed BanI restriction enzyme site; $\left(\mathrm{a}^{\prime}\right)$ polymorphism of PCR-RFLP products of the XRCC6 $-61 \mathrm{C}>\mathrm{G}$ gene in $1 \%$ agarose gel electrophoresis. Lane M: 50 bp DNA ladder; lane 1: CC homozygous genotype; lane 2: CG heterozygous genotype; lane 3: GG homozygous genotype; (b) schematic diagram of XRCC7 6721G>T which showed PvuII restriction enzyme site; (b') polymorphism of PCR-RFLP products of the XRCC7 $6721 \mathrm{G}>\mathrm{T}$ gene in 1\% agarose gel electrophoresis, lane M: 50 bp DNA ladder; lane 1: GG homozygous genotype; lane 2: GT heterozygous genotype; lane 3: TT homozygous genotype.

The prediction of the consequence of XRCC7 -6721G>T mutation via HSF 3 tool showed that this SNP occurred in an acceptor splicing site and the transversion of allele $G$ to allele $\mathrm{T}$ causes the increase of HSF score of the mutation and also increased slightly the upstream acceptor splicing site's HSF score, but not created new cryptic splice acceptor site (Table 4(a)). The intronic variation of $\operatorname{rs7003908~(G>T)~}$ increased branch point sequences as well (Table 4(b)). Screening of the DNA sequence flankings of rs7003908 $(\mathrm{G}>\mathrm{T})$ for enhancer motif, Exonic Splicing Enhancers (ESEs) and Intronic Splicing Enhancers (ISEs), and silencer motif, Exonic Splicing Silencers (ESSs) and Intronic Splicing Silencers (ISSs), by HSF 3 and SpliceAid 2 tools have shown almost same results. This in silico analysis revealed decrease, change, and removal of some of the ESEs such as SR (serine/argine-rich) proteins together with slight increase in ESE motifs from HSF for mutant allele T (Tables 4(c) and 4(d); Figures 6(a) and $\left.6\left(a^{\prime}\right)\right)$.

However, SpliceAid 2 has not shown any change in the silencer motifs (Figures $6(\mathrm{a})$ and $6\left(\mathrm{a}^{\prime}\right)$ ), but HSF 3 displayed an ESS site broken for wild-type allele G and production of a new silencer motif site for mutant allele $\mathrm{T}$ which has potential alteration of splicing (Tables 4(e), 4(f), and 4(g)). Consistent with HSF 3 prediction, subsequent analysis with SplicePort tool showed that XRCC7 $-6721 \mathrm{G}>\mathrm{T}$ is presented in an acceptor site and it is not only decrease score of the mutation and near acceptor sites, but also able to influence on another acceptor or even donor sites (data not shown). The conservation of the XRCC7-6721 in across multiple mammalian species was assessed by GoldenPath tool and illustrated in WebLog (Figure 6(b)).

\section{Discussion}

To the best of our knowledge, the present study was the first demonstration that the XRCC5 VNTR, XRCC6 -61C>G, and $X R C C 76721 \mathrm{G}>\mathrm{T}$ polymorphisms are associated with susceptibility to male infertility. The results of our study showed that carriers of the $2 \mathrm{R}$ allele of XRCC5 VNTR were associated with a significantly decreased risk of male 


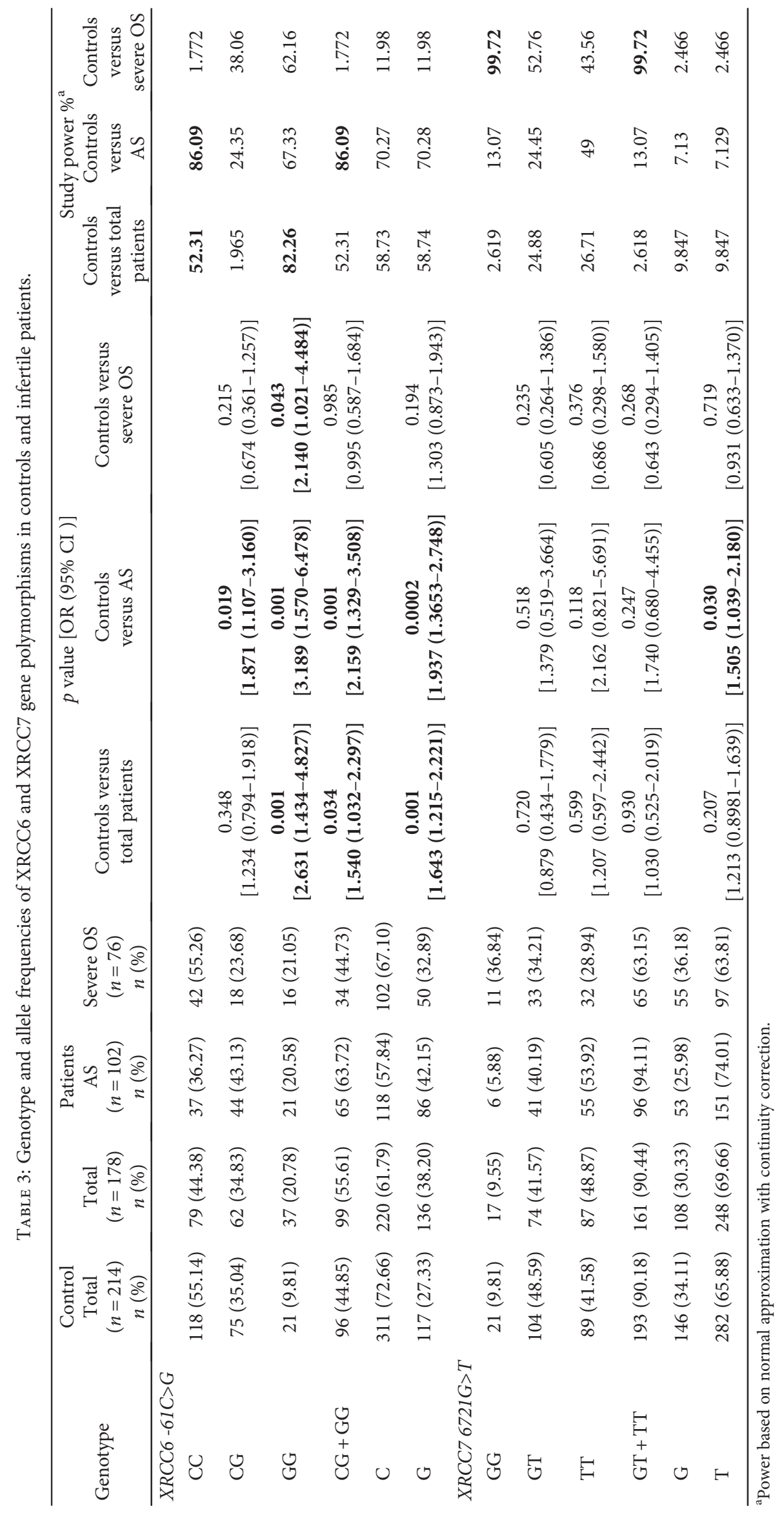




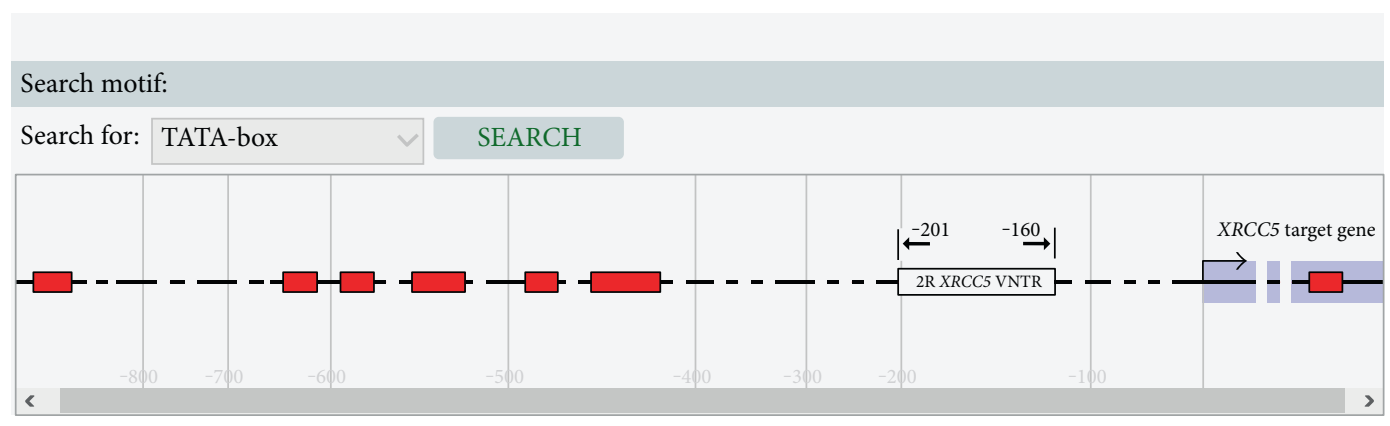

(a)

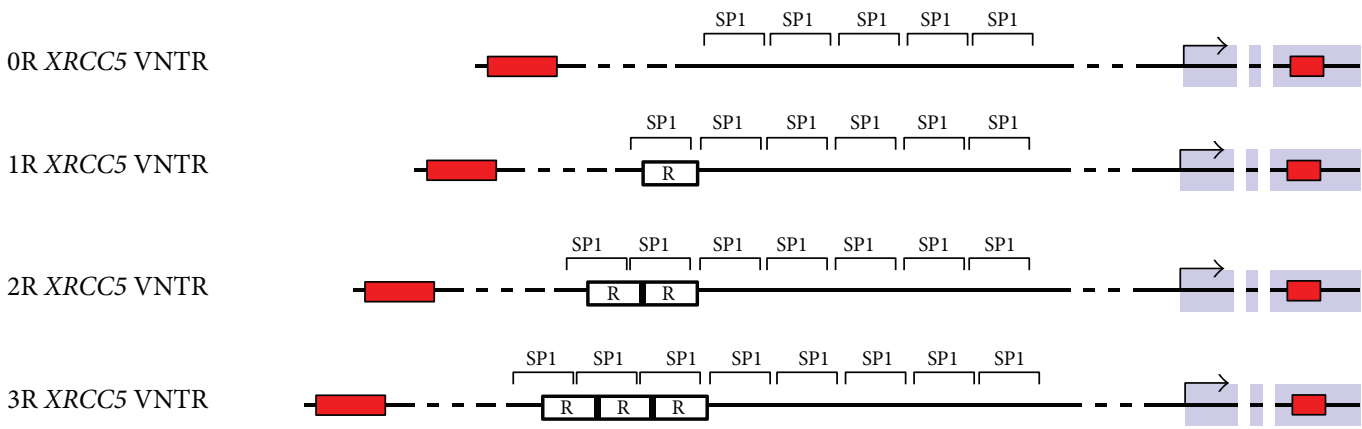

(b)

FIGURE 3: EPD report and schematic diagram of the different alleles of XRCC5 VNTR: (a) EPD report of the TATA-box situations and schematic diagram of VNTR (rs6147172) in the XRCC5 gene promoter; (b) schematic diagram of the different alleles of XRCC5 VNTR $0 R, 1 R, 2 R$, and $3 R$ containing variable numbers of nuclear transcription factor $S p 1$.

infertility. Moreover, the 2R allele of XRCC5 also significantly reduced the risk of male infertility (Table 2 ), suggesting that the presence of $2 \mathrm{R}$ allele in XRCC5 VNTR gene polymorphism may be a protective factor for male infertility. Besides, the mutant GG genotypes as well as carriers of the CG and GG genotypes showed increased risk for the male infertility. Furthermore, the $G$ allele of the XRCC6 -61C>G variant was correlated with increased susceptibility to male infertility (Table 3 ). It suggests that the mutant allele $\mathrm{G}$ of XRCC6 $-61 \mathrm{C}>\mathrm{G}$ could be considered as a risk factor for male infertility susceptibility. Likewise, the $\mathrm{T}$ allele of the XRCC7 6721G>T polymorphism was associated with increased susceptibility to the male infertility in azoospermia (Table 3), which indicates the increased role of this polymorphism on male infertility risk.

Sperm DNA integrity is crucial for perfect transmission of genetic information; therefore, any sperm DNA damage may lead to male infertility despite the number, motility and morphology of spermatozoa, and, consequently, low fertilization rates, suggesting that it has a significant influence on the progeny [2-6]. Because of exogenous and endogenous agent's DNA breaks, a probable case in spermatogenesis together with malfunction of DNA repair mechanisms can affect normal sperm criteria and at last result in male infertility with azoospermia or oligospermia [4-6]. It is manifested that different polymorphic variants of genes encoding the proteins responsible for DNA repair were linked with the development of sperm DNA damage and male infertility [16-21].
NHEJ is a main mechanism for the removal of broad DNA double-strand breaks (DSBs) lesions and has a critical role in maintaining normal spermatogenesis and genetic stability $[13,15]$. DNA-dependent protein kinase (DNAPK) consists of a heterodimer DNA targeting subunit Ku70/Ku80, XRCC6/XRCC5, and catalytic subunit DNAPKcs, XRCC7, which are imperative components of NHEJ which expresses in late spermatocytes of the testis, particularly $[11,13,14]$. All components of the DNA-PK were found in the radiosensitive spermatogonia, and also, it is demonstrated that $\mathrm{Ku}$ ensures the fidelity of spermatogenesis so that the Ku70 and/or Ku80-deficient testis displays elevated levels of DSBs as well as enhanced apoptosis and reduced sperm production $[12,14]$.

The XRCC5 VNTR polymorphism, rs6147172, was located in the promoter region and could affect the transcriptional activity of this gene [27, 41]. Polymorphism of rs6147172 has been implicated in susceptibility to several cancers including bladder cancer [27], acute myeloid leukemia (AML) [26], chronic myeloid leukemia (CML) [23], and autoimmune disease such as SLE [30]. In the current study, we observed that the frequency of $2 \mathrm{R}$ allele and $2 \mathrm{R}$ allele carriers had decreased risk of male infertility which can be considered as a genetic protective factor which was consistent with those previous roles in AML [26], CML [23], and SLE [30].

The strong evidence introduced VNTR sequences in promoter regions as regulatory elements which can bind to nuclear factors and affect transcriptional activity [42]. The 


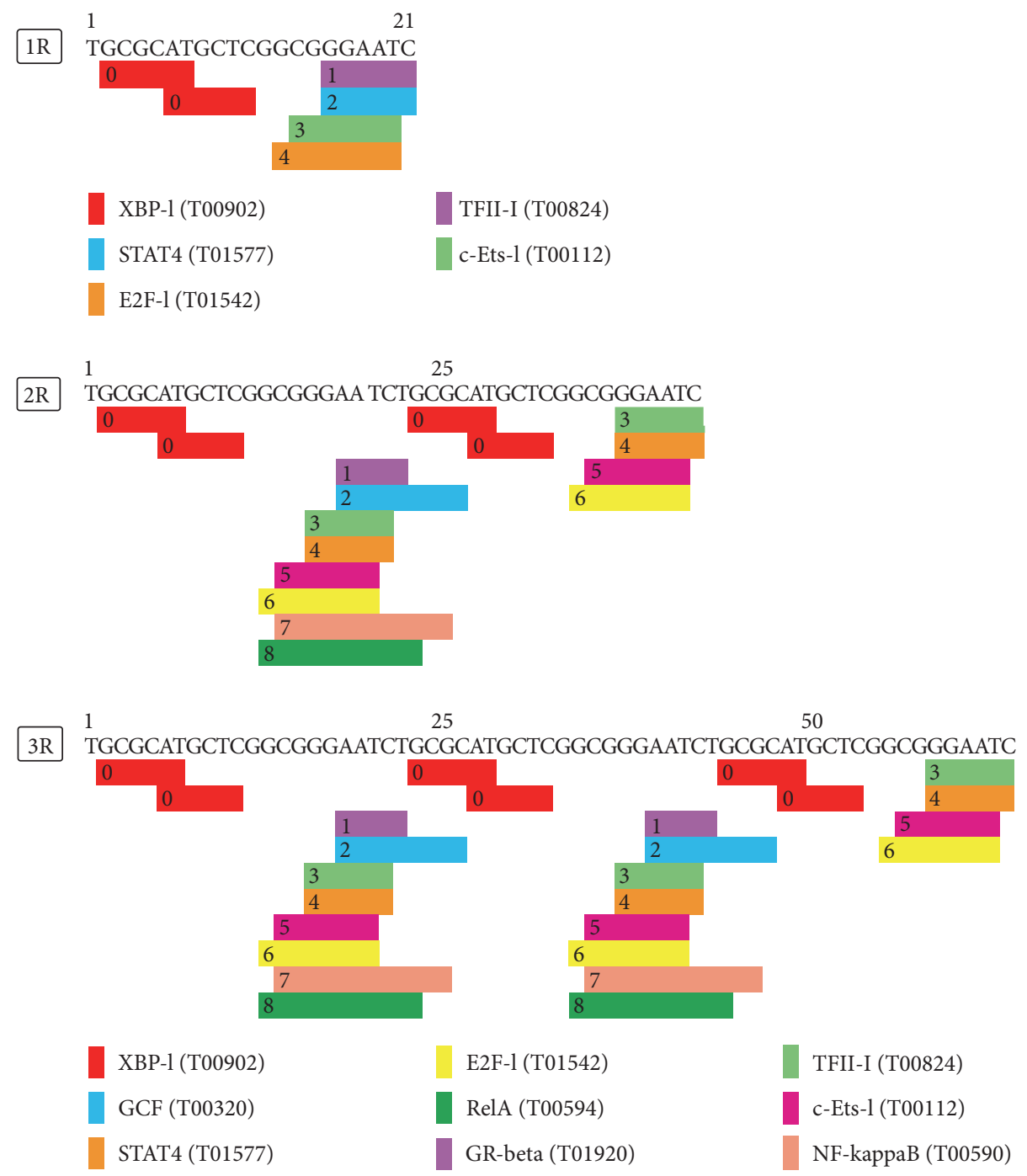

FIgURe 4: Potential binding sites for transcription factors of 1R, 2R, and 3R tandem repeat elements of the XRCC5 VNTR: XBP-1 = X-box binding protein 1; TFII-I = transcription factor II-I; STAT4 = signal transducer and activator of transcription 4; c-Ets-1 = c-E-twenty-six-1; E2F-1 = E2F transcription factor 1; GR-beta=glucocorticoid receptor-beta; GCF=GC factor; NF-kappaB=nuclear factor-kappaB; RelA = v-rel avian reticuloendotheliosis viral oncogene homolog A.

promoter region of XRCC5 contains several copies of Sp1 recognition cis regulatory elements and its gene expression has Sp1-dependent manner (Figure 3(b)) [27, 43]. The VNTR polymorphism of XRCC5 can alter the number of Sp1 elements so that four different alleles of XRCC5 VNTR $3 R, 2 R, 1 R$, and $0 R$ possess eight, seven, six, and five copies of Sp1 elements, respectively [41], which were able to modify the expression of XRCC5 [27, 43]. The in silico analysis of present study showed that the presence of tandem repeats in XRCC5 gene promoter can be sequenced to bind to more nuclear factors and probably affect transcriptional activity (Figure 4). This overactivity of XRCC5 leads to surplus DNA repair, which can increase the resistance of spermatogonia to genotoxic agents and interfere with DNA damagedependent apoptosis and, thus, increase the likelihood for the development of normal sperm during spermatogenesis.

According to results of a newly meta-analysis which was performed on the XRCC6 SNP polymorphisms and cancer risk, the rs2267437 polymorphism was found to be associated with a significant increase in risks of overall cancers, breast cancer, RCC, and HCC, and it might increase the cancer risk in Asian population [25]. The result of current study showed a high association between genetic polymorphism of XRCC6 rs2267437 with male infertility, suggesting that this SNP might be a genetic risk factor for male infertility.

The XRCC6 -61C>G polymorphism, rs2267437, was located in the promoter region and it is established that this SNP could influence the expression level and stability of the $\mathrm{Ku} 70$ protein in breast cancer cells and renal cell carcinoma tissues [44, 45]. Additional in silico analysis of current study to predict biological effects of rs2267437 (C>G) on XRCC6 expression showed that the XRCC6 $-61 C>G$ variant could cause deletion of a BRE upstream element in the XRCC6 promoter, firstly Figure 5(a), and the sequence region around rs2267437 (C>G) was predicated to be a DNA-binding site of 


\begin{tabular}{|c|c|c|c|c|}
\hline Element & Start position & Sequence & PWM score & Consensus match \\
\hline Mammalian initiator & 8 & ССАССТC & 0.1818 & 6 out of 7 \\
\hline Mammalian initiator & 24 & ССАСССТ & 0.1091 & 6 out of 7 \\
\hline Mammalian initiator & 17 & CCAGCCG & 0.0341 & 5 out of 7 \\
\hline BRE upstream & 16 & GCCAGCC & 0.0967 & 5 out of 7 \\
\hline BRE upstream & 19 & AGCCGCC & 0.0510 & 5 out of 7 \\
\hline \multicolumn{5}{|c|}{ XRCC6 -61G: $\mid \leftarrow^{-15}{ }^{-n t}$ GCCAGGCGCCA ${ }^{15} \mathrm{nt} \rightarrow$} \\
\hline Element & Start position & Sequence & PWM score & Consensus match \\
\hline Mammalian initiator & 8 & ССАССТС & 0.1818 & 6 out of 7 \\
\hline Mammalian initiator & 24 & ССАСССТ & 0.1091 & 6 out of 7 \\
\hline Mammalian initiator & 17 & CCAGGCG & 0.0341 & 5 out of 7 \\
\hline BRE upstream & 19 & AGGCGCC & 0.1470 & 6 out of 7 \\
\hline
\end{tabular}

(a)

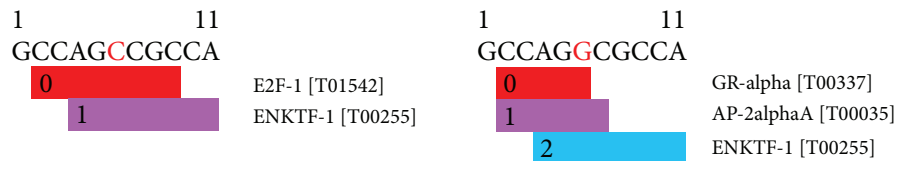

(b)

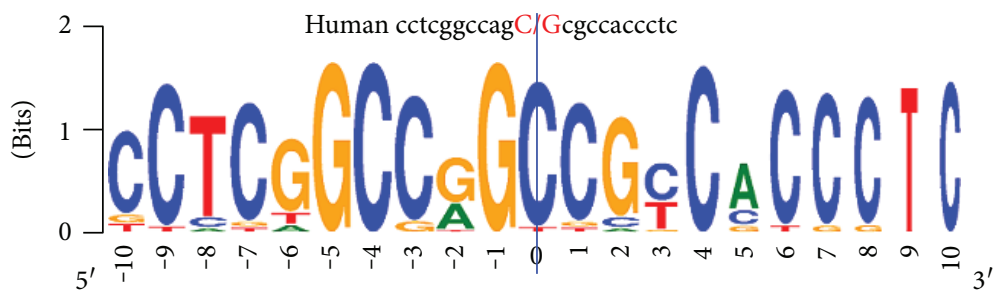

(c)

FIGURE 5: The prediction of core promoter elements, transcription factor binding sites, and sequence conservation of the XRCC6 -61C>G variant in the XRCC6 gene promoter: (a) prediction of core promoter elements via ElemeNT tool; (b) prediction of potential transcription factor binding sites; (c) illustration of sequence conservation of the DNA sequence around rs2267437 (C>G) locus.

E2F1, with the allele $\mathrm{C}$ to allele $\mathrm{G}$ change leading to the loss of this site, secondly Figure 5(b). Also, it was illustrated in WebLogo that rs2267437 (C>G) lies within a high conserved region across mammalian species, which indicates potential function for this variant (Figure 5(c)). Moreover, the sequence variation in the rs2267437 may affect binding activity of the adjacent CACCC box which is extended to their 4-5 upstream nucleotides and is known binding sites for SP1 and other Kruppel-like transcription factors $[44,46]$. The binding and activity of SP1 and Kruppel-like transcription factors are heavily dependent on the SP1/Kruppel-like binding sites and adjacent sequences as well [47]. It has been demonstrated that E2F1 expression was required for the development of male germ cells $[48,49]$. The sequence variation in the rs2267437 may abrogate the E2F1 binding site as well as affect binding activity of the adjacent CACCC box with transcription factors, resulting in decreased Ku70 expression level, and the DSB repair activity thus was affected, finally leading to spermatogenic failure.

Genetic polymorphisms of XRCC7 6721G>T were associated with an increased risk of glioma [22], bladder cancer [28], and SLE [30], while other studies reported that there were no significant associations between this polymorphism and risk of renal cell carcinoma and differentiated thyroid cancer $[24,29]$. Our result further supports that the polymorphism of the XRCC7 $6721 \mathrm{G}>\mathrm{T}$ may be a genetic risk factor for azoospermic male infertile but not for total infertile and severe oligozoospermia (Table 3).

Defects and alterations in pre-mRNA splicing have been revealed as a common disease-causing mechanism in several studies [50, 51]. Because the XRCC7 6721G>T polymorphism, rs7003908, was located in the intron 8 of $X R C C 7$ gene, auxiliary in silico analysis was performed to predict the effects of this variation on XRCC7 mRNA splicing. Bioinformatics analysis showed that although this SNP occurred in an acceptor splicing site and the transversion of allele $\mathrm{G}$ to allele $\mathrm{T}$ in XRCC7 6721 causes alterations such as increase in the score of the mutation and branch point sequences and can decrease, change, and remove some of the ESEs and also able to produce a new silencer motifs site which has potential alteration of splicing (Table 4 and Figure 6(a)), this variation cannot create new cryptic splice acceptor site, so this gene polymorphism has not severe modification on XRCC7 mRNA splicing. Moreover, it was illustrated in WebLogo that rs7003908 (G>T) was mapped within a slight conserved region across mammalian species, which indicates relative function for this variant (Figure 6(b)).

However, the functional significance of XRCC7 intron G6721T polymorphism is unknown; this single-nucleotide polymorphism might affect slightly the XRCC7 mRNA splicing and, thus, decrease the level of protein expression in splicing stages, which can affect DNA repair pathway and reduce the resistance of the cells against genotoxic agents in azoospermic male infertile patients' result. However, these possibilities should be investigated in future studies.

As an important pathway in the DNA damage repair network-NHEJ-XRCC5, XRCC6, and XRCC7 play a critical role in the maintenance of genetic integrity. Thus, it would 


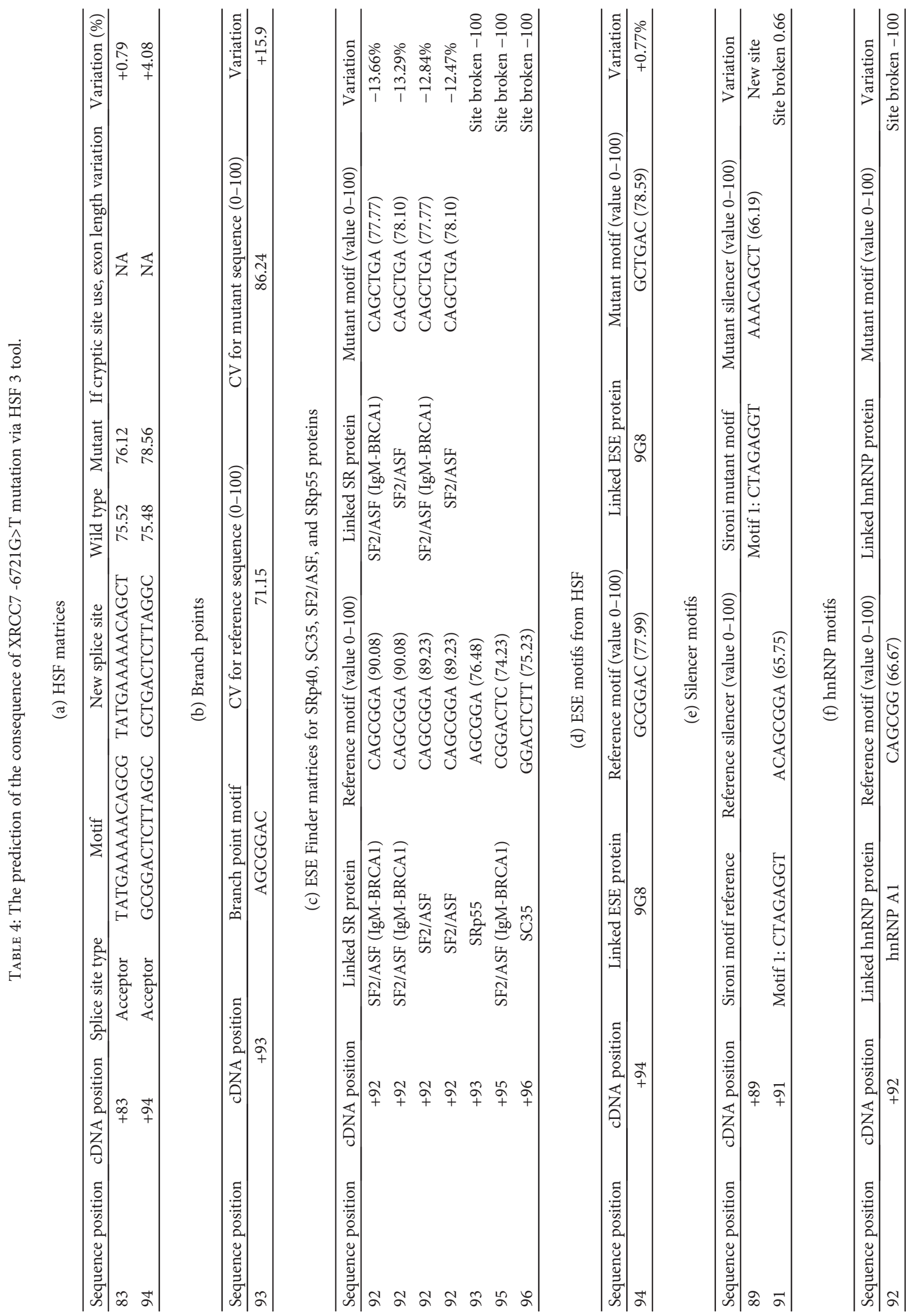




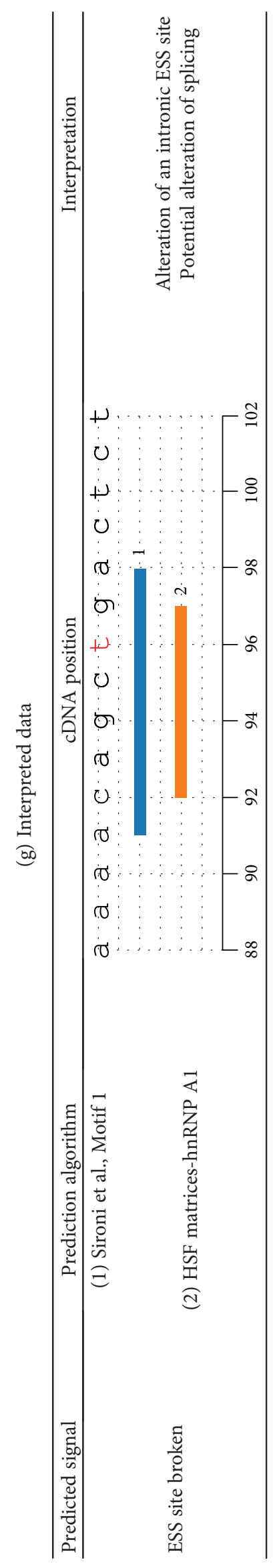




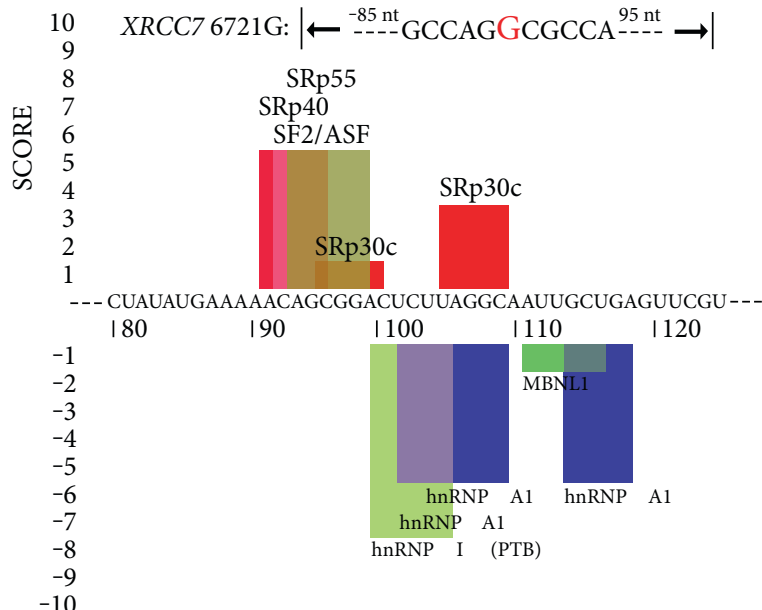

(a)

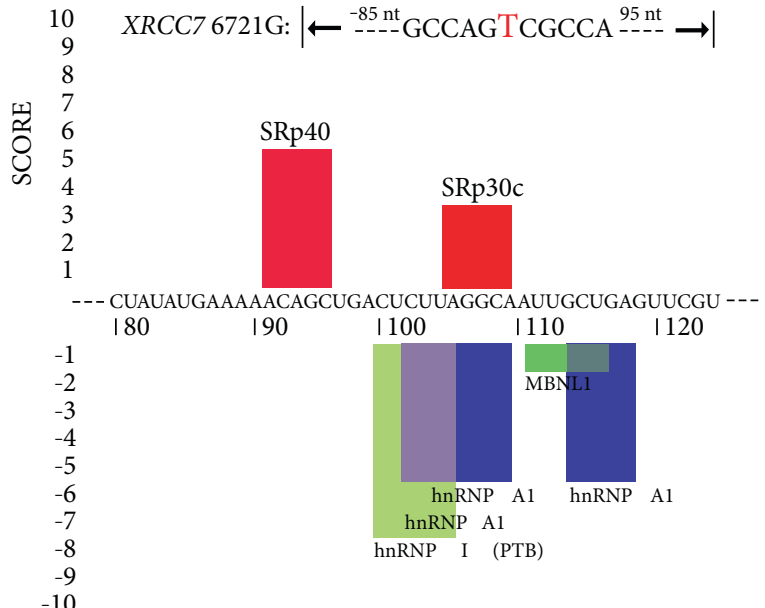

$\left(\mathrm{a}^{\prime}\right)$

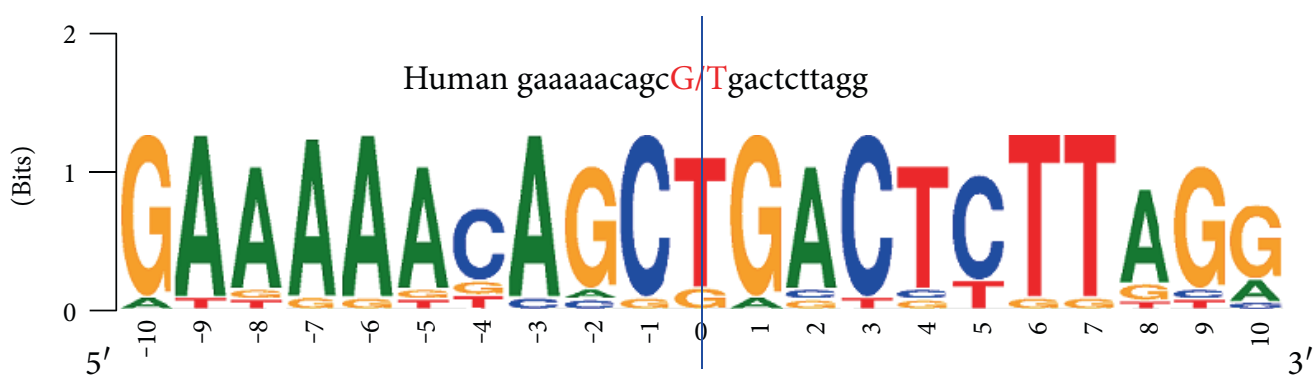

(b)

FIGURE 6: Enhancers and silencers of the XRCC7 6721G>T DNA sequence flanking motif and its sequence conservation: screening of the DNA sequence flankings of XRCC7 6721G $>$ T for enhancer and silencer motif via SpliceAid 2 tool (a and $a^{\prime}$ ); illustration of sequence conservation of the XRCC7 6721 across multiple mammalian species (b).

be supposed that these three significant SNPs that affect sperm DNA integrity could also modify male infertility risk. However, our result showed significant association between XRCC5, XRCC6, and XRCC7 gene polymorphisms and male infertility in an Iranian cohort. However, experimental studies are necessary to confirm such an assumption in the future.

In conclusion, this study provided evidences that the XRCC5 VNTR, XRCC6, and XRCC7 6721G>T gene polymorphisms were associated with male infertility risk. Large cohort and diverse ethnicity studies as well as further functional analysis are needed to elucidate the biological mechanism of these polymorphisms of XRCC5, XRCC6, and XRCC7 in male infertility.

\section{Conflicts of Interest}

The authors have declared that no conflicts of interest exist.

\section{Acknowledgments}

The authors thank Dr. Seyed Gholam Ali Jorsarayi, from Fatemeh Zahra Hospital (Babol, Iran), for recruiting the case and control volunteers. They are grateful to Mrs. Maryam Moossavi and their colleagues in the Molecular and Cell
Biology Laboratory of the University of Mazandaran for critical reviews of the manuscript.

\section{References}

[1] V. M. Brugh and L. I. Lipshultz, "Male factor infertility: evaluation and management," The Medical Clinics of North America, vol. 88, no. 2, pp. 367-385, 2004.

[2] M. Benchaib, J. Lornage, C. Mazoyer, H. Lejeune, B. Salle, and J. F. Guerin, "Sperm deoxyribonucleic acid fragmentation as a prognostic indicator of assisted reproductive technology outcome," Fertility and Sterility, vol. 87, no. 1, pp. 93-100, 2007.

[3] S. Lewis and R. Aitken, "DNA damage to spermatozoa has impacts on fertilization and pregnancy," Cell and Tissue Research, vol. 322, no. 1, pp. 33-41, 2005.

[4] A. Agarwal and T. M. Said, "Role of sperm chromatin abnormalities and DNA damage in male infertility," Human Reproduction Update, vol. 9, no. 4, pp. 331-345, 2003.

[5] A. Borini, N. Tarozzi, D. Bizzaro et al., "Sperm DNA fragmentation: paternal effect on early post-implantation embryo development in ART," Human Reproduction, vol. 21, no. 11, pp. 2876-2881, 2006.

[6] P. Cohen-Bacrie, S. Belloc, Y. J. Ménézo, P. Clement, J. Hamidi, and M. Benkhalifa, "Correlation between DNA damage and sperm parameters: a prospective study of 1,633 patients," Fertility and Sterility, vol. 91, no. 5, pp. 1801-1805, 2009. 
[7] M. E. Dresser, "Meiotic chromosome behavior in Saccharomyces cerevisiae and (mostly) mammals," Mutation Research, vol. 451, no. 1, pp. 107-127, 2000.

[8] M. Gellert, J. Hesse, K. Hiom et al., "V(D)J recombination: links to transposition and double-strand break repair," Cold Spring Harbor Symposia on Quantitative Biology, vol. 64, pp. 161-167, 1999.

[9] K. K. Khanna and S. P. Jackson, "DNA double-strand breaks: signaling, repair and the cancer connection," Nature Genetics, vol. 27 , no. 3, pp. 247-254, 2001.

[10] M. R. Lieber, "The mechanism of double-strand DNA break repair by the nonhomologous DNA end joining pathway," Annual Review of Biochemistry, vol. 79, pp. 181-211, 2010.

[11] E. A. Ahmed, M. E. Philippens, H. B. Kal, D. G. de Rooij, and P. de Boer, "Genetic probing of homologous recombination and non-homologous end joining during meiotic prophase in irradiated mouse spermatocytes," Mutation Research, vol. 688, no. 1, pp. 12-18, 2010.

[12] E. A. Ahmed, A. Sfeir, H. Takai, and H. Scherthan, "Ku70 and non-homologous end joining protect testicular cells from DNA damage," Journal of Cell Science, vol. 126, no. 14, pp. 3095-3104, 2013.

[13] E. A. Ahmed, A. van der Vaart, A. Barten et al., "Differences in DNA double strand breaks repair in male germ cell types: lessons learned from a differential expression of $\mathrm{Mdcl}$ and 53BP1,” DNA Repair, vol. 6, no. 9, pp. 1243-1254, 2007.

[14] C. Couëdel, K. D. Mills, M. Barchi et al., "Collaboration of homologous recombination and nonhomologous end-joining factors for the survival and integrity of mice and cells," Genes \& Development, vol. 18, no. 11, pp. 1293-1304, 2004.

[15] G. Hamer, H. L. Roepers-Gajadien, A. van Duyn-Goedhart et al., "Function of DNA-protein kinase catalytic subunit during the early meiotic prophase without Ku70 and Ku86," Biology of Reproduction, vol. 68, no. 3, pp. 717-721, 2003.

[16] A. Gu, G. Ji, Y. Zhou et al., "Polymorphisms of nucleotideexcision repair genes may contribute to sperm DNA fragmentation and male infertility," Reproductive Biomedicine Online, vol. 21, no. 5, pp. 602-609, 2010.

[17] G. Ji, A. Gu, Y. Xia et al., "ERCC1 and ERCC2 polymorphisms and risk of idiopathic azoospermia in a Chinese population," Reproductive Biomedicine Online, vol. 17, no. 1, pp. 36-41, 2008.

[18] G. Ji, A. Gu, P. Zhu et al., "Joint effects of XRCC1 polymorphisms and polycyclic aromatic hydrocarbons exposure on sperm DNA damage and male infertility," Toxicological Sciences, vol. 116, no. 1, pp. 92-98, 2010.

[19] G. Ji, Y. Long, Y. Zhou, C. Huang, A. Gu, and X. Wang, "Common variants in mismatch repair genes associated with increased risk of sperm DNA damage and male infertility," BMC Medicine, vol. 10, p. 49, 2012.

[20] G. Ji, L. Yan, W. Liu, C. Huang, A. Gu, and X. Wang, "Polymorphisms in double-strand breaks repair genes are associated with impaired fertility in Chinese population," Reproduction, vol. 145, no. 5, pp. 463-470, 2013.

[21] J. Liang, A. Gu, Y. Xia et al., "XPC gene polymorphisms and risk of idiopathic azoospermia or oligozoospermia in a Chinese population," International Journal of Andrology, vol. 32, no. 3, pp. 235-241, 2009.

[22] L.-E. Wang, M. L. Bondy, H. Shen et al., "Polymorphisms of DNA repair genes and risk of glioma," Cancer Research, vol. 64, no. 16, pp. 5560-5563, 2004.
[23] M. Gorre, P. E. Mohandas, S. Kagita, S. Annamaneni, R. Digumarti, and V. Satti, "Association of XRCC5 VNTR polymorphism with the development of chronic myeloid leukemia," Tumour Biology, vol. 35, no. 2, pp. 923-927, 2014.

[24] H. Hirata, Y. Hinoda, H. Matsuyama et al., "Polymorphisms of DNA repair genes are associated with renal cell carcinoma," Biochemical and Biophysical Research Communications, vol. 342, no. 4, pp. 1058-1062, 2006.

[25] J. Jia, J. Ren, D. Yan, L. Xiao, and R. Sun, "Association between the XRCC6 polymorphisms and cancer risks: a systematic review and meta-analysis," Medicine, vol. 94, no. 1, Article ID e283, 2015.

[26] G. Wang, S. Wang, Q. Shen et al., "Polymorphisms in XRCC5, XRCC6, XRCC7 genes are involved in DNA double-strand breaks (DSBs) repair associated with the risk of acute myeloid leukemia (AML) in Chinese population," Journal of Nanjing Medical University, vol. 23, no. 2, pp. 93-99, 2009.

[27] S. Wang, M. Wang, S. Yin et al., "A novel variable number of tandem repeats (VNTR) polymorphism containing Sp1 binding elements in the promoter of XRCC5 is a risk factor for human bladder cancer," Mutation Research, vol. 638, no. 1, pp. 26-36, 2008.

[28] Y. Zhi, J. Yu, Y. Liu et al., "Interaction between polymorphisms of DNA repair genes significantly modulated bladder cancer risk," International Journal of Medical Sciences, vol. 9, no. 6, pp. 498-505, 2012.

[29] A. C. Guilhen, N. E. Bufalo, and E. C. Morari, "Radiation response genotype and risk of differentiated thyroid cancer: a casecontrol analysis," Laryngoscope, vol. 9, no. 6, pp. 498505,2012

[30] D. Jahantigh, S. Salimi, M. Mousavi et al., "Association between functional polymorphisms of DNA double-strand breaks in repair genes XRCC5, XRCC6 and XRCC7 with the risk of systemic lupus erythematosus in South East Iran," DNA and Cell Biology, vol. 34, no. 5, pp. 360-366, 2015.

[31] D. Jahantigh, A. Moghtaderi, M. Narooie-Nejad et al., "Carriage of $2 \mathrm{R}$ allele at VNTR polymorphous site of XRCC5 gene increases risk of multiple sclerosis in an Iranian population," Russian Journal of Genetics, vol. 53, no. 1, pp. 147-152, 2017.

[32] R. C. Périer, V. Praz, T. Junier, C. Bonnard, and P. Bucher, "The eukaryotic promoter database (EPD)," Nucleic Acids Research, vol. 28, no. 1, pp. 302-303, 2000.

[33] A. Sloutskin, Y. M. Danino, Y. Orenstein et al., "ElemeNT: a computational tool for detecting core promoter elements," Transcription, vol. 6, no. 3, pp. 41-50, 2015.

[34] A. Z. Dayem Ullah, N. R. Lemoine, and C. Chelala, "SNPnexus: a web server for functional annotation of novel and publicly known genetic variants (2012 update)," Nucleic Acids Research, vol. 40, pp. W65-W70, 2012.

[35] X. Messeguer, R. Escudero, D. Farré, O. Núñez, J. Martínez, and M. M. Albà, "PROMO: detection of known transcription regulatory elements using species-tailored searches," Bioinformatics, vol. 18, no. 2, pp. 333-334, 2002.

[36] F. O. Desmet, D. Hamroun, M. Lalande, G. Collod-Béroud, M. Claustres, and C. Béroud, "Human Splicing Finder: an online bioinformatics tool to predict splicing signals," Nucleic Acids Research, vol. 37, no. 9, Article ID e67, 2009.

[37] F. Piva, M. Giulietti, A. B. Burini, and G. Principato, "SpliceAid 2: a database of human splicing factors expression data 
and RNA target motifs," Human Mutation, vol. 33, no. 1, pp. 81-85, 2012.

[38] R. I. Dogan, L. Getoor, W. J. Wilbur, and S. M. Mount, "SplicePort-an interactive splice-site analysis tool," Nucleic Acids Research, vol. 35, pp. W285-W291, 2007.

[39] M. L. Speir, A. S. Zweig, K. R. Rosenbloom et al., "The UCSC Genome Browser database: 2016 update," Nucleic Acids Research, vol. 44, no. D1, pp. D717-D725, 2016.

[40] G. E. Crooks, G. Hon, J. M. Chandonia, and S. E. Brenner, "WebLogo: a sequence logo generator," Genome Research, vol. 14, no. 6, pp. 1188-1190, 2004.

[41] M. Rajaei, I. Saadat, and M. Saadat, "The novel allele (3R) of the VNTR polymorphism in the XRCC5 promoter region dramatically decreases the gene expression," Biochemical and Biophysical Research Communications, vol. 430, no. 2, pp. 640-641, 2013.

[42] Y. Nakamura, K. Koyama, and M. Matsushima, "VNTR (variable number of tandem repeat) sequences as transcriptional, translational, or functional regulators," Journal of Human Genetics, vol. 43, no. 3, pp. 149-152, 1998.

[43] Y. Hosoi, T. Watanbe, K. Nakagawa et al., "Up-regulation of DNA-dependent protein kinase activity and Sp1 in colorectal cancer," International Journal of Oncology, vol. 25, no. 2, pp. 461-468, 2004.

[44] M. Ouimet, P. Cassart, M. Larivière, E. A. Kritikou, J. Simard, and D. Sinnett, "Functional analysis of promoter variants in KU70 and their role in cancer susceptibility," Genes, Chromosomes \& Cancer, vol. 51, no. 11, pp. 1007-1013, 2012.

[45] W. Wang, X. Pan, X. Huo et al., "A functional polymorphism $\mathrm{C}-1310 \mathrm{G}$ in the promoter region of Ku70/XRCC6 is associated with risk of renal cell carcinoma," Molecular Carcinogenesis, vol. 51, pp. E183-E190, 2012.

[46] Z. Y. Chen, J. L. Shie, and C. C. Tseng, "Gut-enriched Kruppellike factor represses ornithine decarboxylase gene expression and functions as checkpoint regulator in colonic cancer cells," The Journal of Biological Chemistry, vol. 277, no. 48, pp. 46831-46839, 2002.

[47] N. M. Hasan and M. J. MacDonald, "Sp/Krüppel-like transcription factors are essential for the expression of mitochondrial glycerol phosphate dehydrogenase promoter B," Gene, vol. 296, no. 1-2, pp. 221-234, 2002.

[48] K. S. El-Darwish, M. Parvinen, and J. Toppari, "Differential expression of members of the E2F family of transcription factors in rodent testes," Reproductive Biology and Endocrinology, vol. 4, p. 63, 2006.

[49] M. R. Hoja, J. G. Liu, M. Mohammadieh, U. Kvist, and L. Yuan, "E2F1 deficiency impairs murine spermatogenesis and augments testicular degeneration in SCP3nullizygous mice," Cell Death and Differentiation, vol. 11, no. 3, pp. 354-356, 2004.

[50] T. A. Cooper, L. Wan, and G. Dreyfuss, "RNA and disease," Cell, vol. 136, no. 4, pp. 777-793, 2009.

[51] J. Tazi, N. Bakkour, and S. Stamm, "Alternative splicing and disease," Biochimica et Biophysica Acta, vol. 1792, no. 1, pp. 14-26, 2009. 


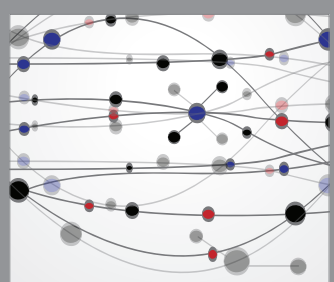

The Scientific World Journal
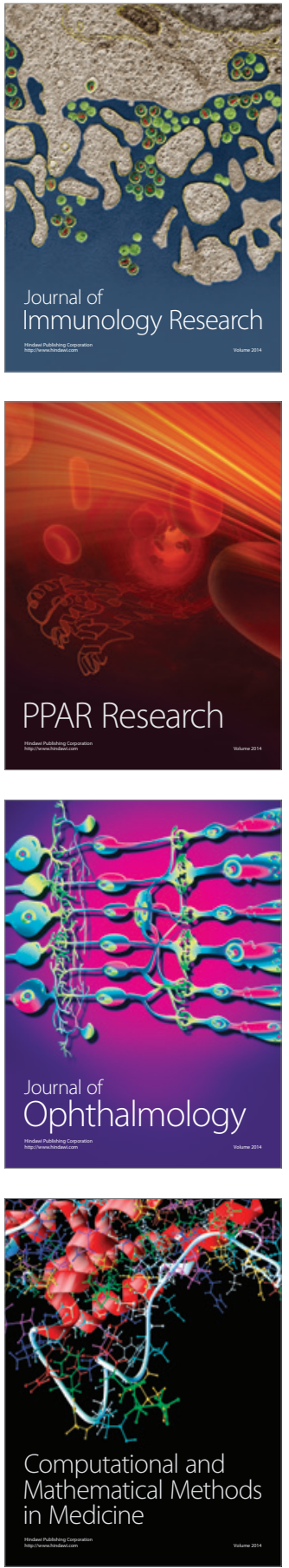

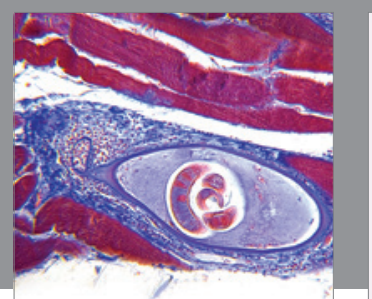

Gastroenterology Research and Practice
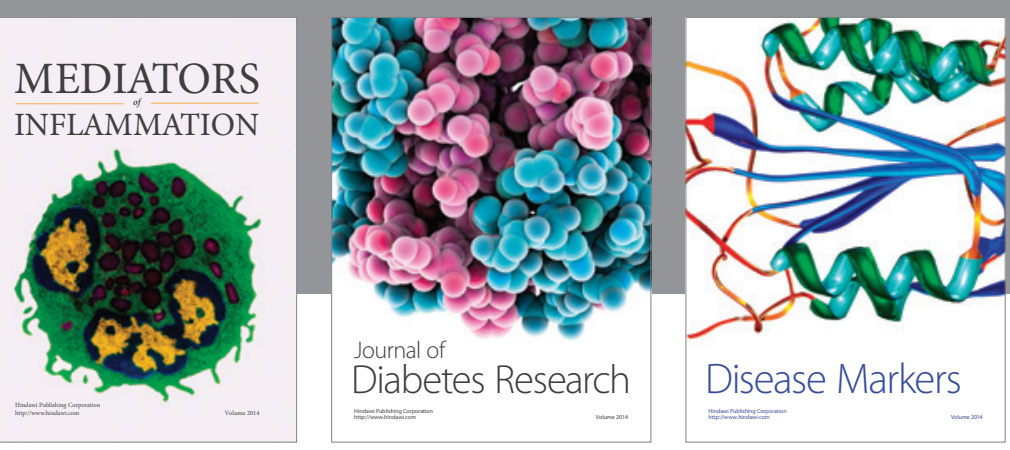

Disease Markers

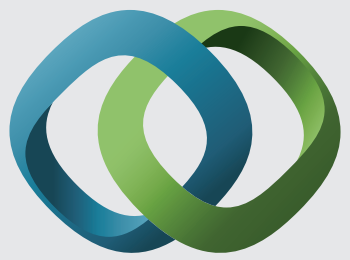

\section{Hindawi}

Submit your manuscripts at

https://www.hindawi.com
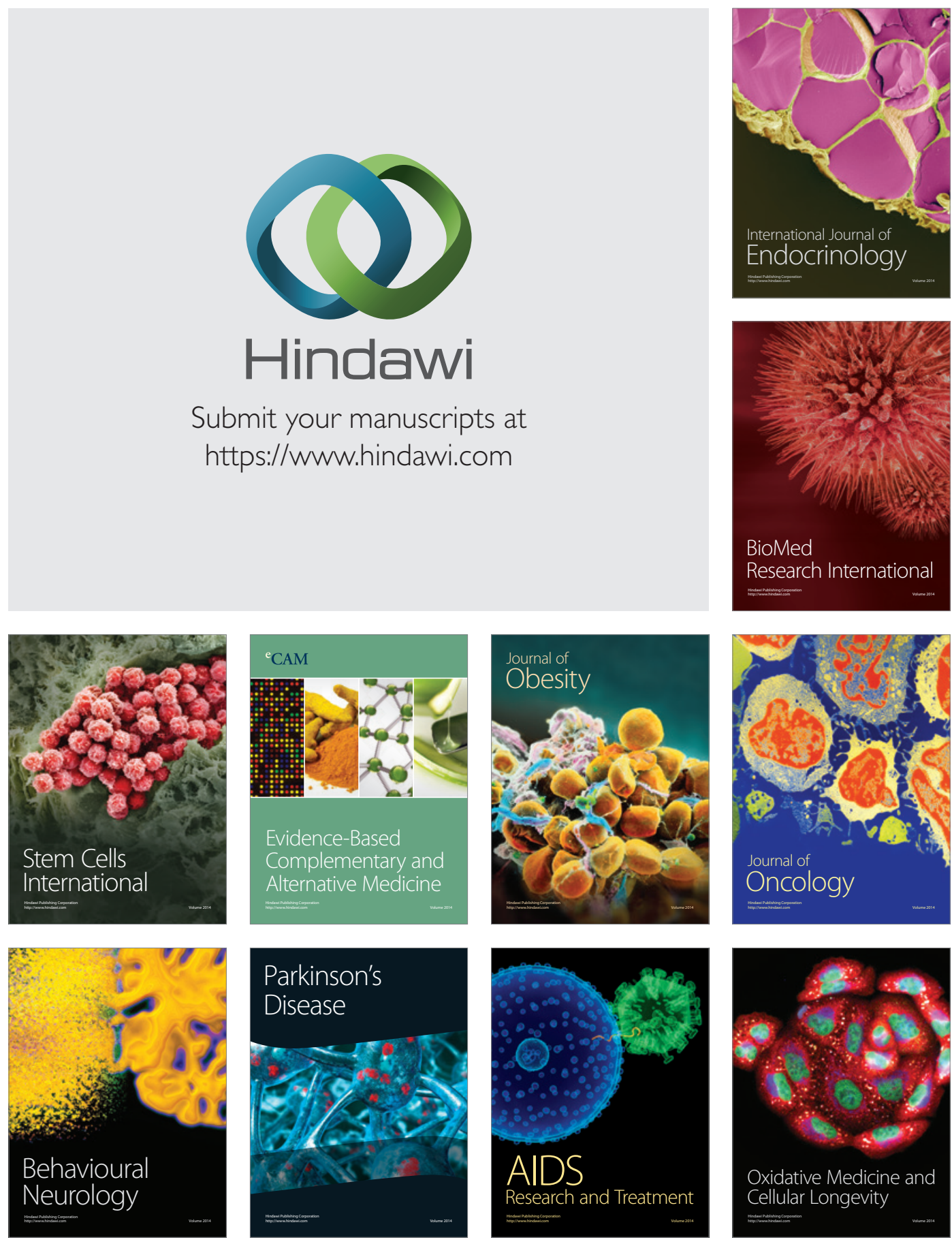